\title{
FABRICATION AND CHARACTERIZATION OF UHMWPE REINFORCED BY FORSTERITE NANO CRYSTALLITES AS AN IMPLANT BIOCOMPOSITE
}

\author{
"MEHRAN JABERZADEH, RAHMATOLLAH EMADI \\ Department of Materials Engineering, Isfahan University of Technology (IUT), \\ Isfahan, Iran \\ "E-mail: mehran.jaberzadeh@gmail.com
}

Submitted September 1, 2015; accepted March 1, 2016

\begin{abstract}
Keywords: Composite, Forsterite, UHMWPE, Implant, Nano Crystallite
Forsterite nano crystallite was synthesized by mixing Talc and $\mathrm{MgCO}_{3}$ in a ball mill for ten hours and then heating at $1000^{\circ} \mathrm{C}$ for ten minutes. Using twin-screw extrusion and then compression molding, an ultra high molecular weight polyethylene (UHMWPE) reinforced by forsterite nano crystallites with volume fraction of 0/5 was produced as a composite sheet. Scanning electron microscopy images showed homogeneous distribution of forsterite particles in the UHMWPE matrix with size scale of less than $1 \mu \mathrm{m}$. In vitro evaluation test in simulated body fluid (SBF) solution revealed the bioactivity of this composite. Mechanical properties of the produced composite were then evaluated using standard tensile test. Results showed that this composite has a strong Young's modulus which is ten times higher than that of pure UHMWPE. In addition, the excellent toughness of pure UHMWPE was approximately maintained using 0/5 volume fraction of forsterite nano crystallite which is gained by over $300 \%$ fracture strain.
\end{abstract}

\section{INTRODUTION}

Due to designing, manufacturing, and laboratory challenges, bio-composite materials have not yet found their ways into widespread commercial applications as implants $[1,2]$. This is while such materials have developed remarkably in orthopaedic uses thanks to their appropriate biological and mechanical properties [3]. Polyethylene composite reinforced by Hydroxyapatite (HA) is one of the best polymer nano-composites for implantation [2,4]; nonetheless, having low yield stress compared to cortical bone, confines its application to non-load bearing implants only [4].

Numerous ways have been tested to develop mechanical properties of bio-composites and extend their uses as implants [3]. One of them is using stronger polymers as the matrix of bio-composites [3]; for example, up to now, polyether ether ketone (PEEK) [5] and poly methyl methacrylate (PMMA) [6] have been put to use as a matrix of bio-composite implants in order to enhance the stiffness and strength of such materials; nonetheless, they are too brittle to be made as a suitable replacement for human bones [3]. Another way to improve the mechanical features of bio-composites is done through strengthening the interface adhesion between particles and matrix [7]; but this method requires adding some coupling agents which causes a reduction in bioactivity of reinforcements [3]. Researchers [8,9] have found that reduction in the size of reinforcement particles and increment of their percentage in the matrix result in better mechanical properties of the composites; however, they have reported that the reinforcement particles should have a size smaller than micron in order to produce mechanical properties comparable to that of bones [3].

In general, bone can be considered as an excellent example of a natural nano-composite made of two main nano-metric size phases: minerals and protein [3]. The mineral phase is mostly made up of HA while the protein phase has mostly made by Collagen [10-12]. To obtain mechanical properties similar to that of natural bone for fabricated bio-composites, they must have a bonelike microstructure [3]. Hence, due to the fact that polymer nano-composites reinforced by bioactive ceramics have the closest likeness to natural bone in mechanical properties, using nano-metric ceramics as reinforcement in polymer matrix seems to be an appropriate choice to gain micro-structural and mechanical properties of the bone [13-15].

Findings of experiments on forsterite show that this ceramic is biocompatible and has got no toxic effects on body cells [16]. Furthermore, forsterite has better mechanical properties, such as higher stiffness, fracture toughness, and elasticity modules in comparison with HA [17-20], to be used as reinforcement in ultra high molecular weight poly ethylene (UHMWPE) matrix. However, ceramic weight changes and the way SBF solution ions change vindicate the point that high grain size forsterite is not bioactive, in spite of its biocompatibility with human body [19]. In 2009, Kharaziha [21] examined the level of bioactivity of nano structural forsterite powder through floating it in SBF solution. The results revealed that this type of forsterite is bioactive. 
As a result, in the current study, nano structural forsterite was put to use as the reinforcement to reach structural and mechanical properties of the bone. Hence, a UHMWPE bioactive composite reinforced by nano structural forsterite was produced and its biological and mechanical features were examined.

\section{EXPERINEMTAL}

\section{Production of \\ Forsterite/UHMWPE composite}

Mechanical activation method [22] was used to produce forsterite powder using a ball mill made up of a Zirconium cylindrical container comprised of four Zirconium balls with the diameter of $2 \mathrm{~cm}$ and average weight of $23 \mathrm{~g}$. The weight proportion of the balls to the powder and the speed were chosen 10:1 and $300 \mathrm{rpm}$ respectively. In so doing, $4.85 \mathrm{~g}$ of $\mathrm{MgCO}_{3}$ (Merk, Germany, with more than $99 \%$ purity and average particle size of $2 \mu \mathrm{m}$ ) was mixed with $4.35 \mathrm{~g}$ of Talc powder (Aldrich, Germany, with more than $99 \%$ purity and average particle size of $10 \mu \mathrm{m}$ ). Then the mixture was ballmilled for 10 hours. Afterwards, the outcome was heated at the temperature of $1000^{\circ} \mathrm{C}$ for 10 minutes. The forsterite powder and UHMWPE reactor powder (Petrochemical Co. of Arak, Iran, with the purity of more than $99 \%$ and average particle size of $200 \mu \mathrm{m}$ and a weight average molecular weight of $6 \times 10^{6} \mathrm{~g} \cdot \mathrm{mol}^{-1}$ ) were mixed and homogenized with forsterite volume fraction $0.5\left(\mathrm{~V}_{\text {forsterite }}=0.5\right)$ using ball mill. Then, the obtained mixture was compounded in a twin-screw extrusion (Bra Bender, Germany). The extrudate was then pelletized into small pieces and compression molded by hot press $\left(230^{\circ} \mathrm{C}, 10 \mathrm{MPa}\right)$ to produce sheets.

\section{Characterisation of}

Forsterite/UHMWPE composite

X-ray diffractometer (XRD, Phillips X'pert-MPD, using Ni filtered $\mathrm{Cu} \mathrm{K} \alpha$ with $\lambda_{\mathrm{Cu}} \mathrm{K}_{\alpha}=0.154 \mathrm{~nm}$, radiation at $40 \mathrm{kV}$ and $30 \mathrm{~mA}$ ) was applied to study phase structure of produced forsterite powder, specify forsterite crystallites size, examine phase structure of composite, and determine the size of forsterite crystallites in UHMWPE matrix. The obtained diffractometer patterns (time per step: $1 \mathrm{~s}$ and step size: $0.04^{\circ}$ ) were with the range of $20<2 \theta<60$ degrees for forsterite and $10<$ $<2 \theta<100$ degrees for composite. The patterns obtained from XRD tests were then compared to standards gathered by JCDPS [23]. The crystallite size of forsterite was measured by Williamson \& Hall Equation [21]. Transmission electron microscopy (TEM, LEO 912 AB) was put to use to study the morphology of particles and measure the size scale of the produced forsterite. In addition, scanning electron microscopy (SEM, Philips XL30) was employed to investigate the size variation and distribution of forsterite particles in UHMWPE matrix. In order to specifying the tensile mechanical properties of forsterite/UHMWPE composite, it underwent tensile testing [3]. To perform this test according to ASTM D638 type IV [24], the produced compression molded sheet was cut into standard specimens with thickness of $0.62 \pm 0.08 \mathrm{~mm}$ and width of $5.89 \pm 0.03 \mathrm{~mm}$. The tensile tests were performed using a tensile testing machine (Zwick/material prufung, Germany). At first, the specimens were stretched with the speed of $2.5 \mathrm{~mm} \cdot \mathrm{min}^{-1}$ up to their $3 \%$ of elongation for accurate measurement of Young's modulus from the linear part of the stressstrain curves [3]. The extensions of specimens were precisely recorded using an extensometer. The tensile tests were then conducted with the speed of $50 \mathrm{~mm} \cdot \mathrm{min}^{-1}$ up to their failure to determine specimens' yield strength and break strain [3]. To ensure accurate measurement of mechanical properties and avoid any undesired error, the tests were repeated for five identical specimens and the average measures have been reported.

\section{In vitro evaluation}

In order to evaluate in vitro bioactivity, simulated body fluid (SBF) solution prepared by kokubo [25] method was applied. In so doing, the obtained forsterite/ UHMWPE composite was floated in the SBF solution at the solid/liquid ratio of $1.5 \mathrm{mg} \mathrm{ml}^{-1}$ for $1,7,14,21$, and 28 days and cured in a bathroom with a fixed temperature of $37^{\circ} \mathrm{C}$. Note that this ratio is quite common and widely used by experts to study the in vitro bioactivity of biomaterials [21]. The $\mathrm{pH}$ of the solution was also recorded each day using an electrolyte-type $\mathrm{pH}$ meter. The specimens were then taken out, rinsed with water and dried at $100^{\circ} \mathrm{C}$ for one day. In order to study the presence of Calcium Phosphate(C-P) and investigate the morphology of the precipitates on the surface of specimens, X-ray Diffractometer (XRD, Phillips X'pertMPD), scanning electron microscopy (SEM, Philips XL30) and energy dispersive X-ray (EDX, Phillips, AIS200) were used. Using EDX, the presence of Calcium and Phosphor on the aforementioned samples could be proven.

\section{RESULTS AND DISCUSSION}

\section{Characterization and microstructure}

Figure 1 represents the outcome of X-ray deffractometer (XRD) test on produced forsterite. This figure shows that only pure forsterite phase is identifiable; in addition, no secondary destructive phase was observed due to 10 minutes heating. The size of forsterite crystallites were equal to $30 \mathrm{~nm}$ which was computed applying Williamson-Hall Equation. Figure 2 is the TEM micrograph for forsterite which shows creation of uniform sized and spherical shape particles. According 
to this figure, the average size of forsterite particles is $50 \mathrm{~nm}$ which agrees with the results obtained from Williamson-Hall Equation. Forsterite particles of this size are bioactive and can produce bone making materials in contact with bio-environment [22].

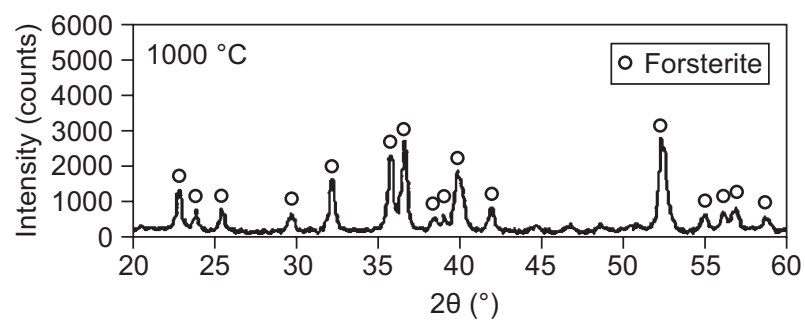

Figure 1. XRD pattern of the synthesized forsterite.

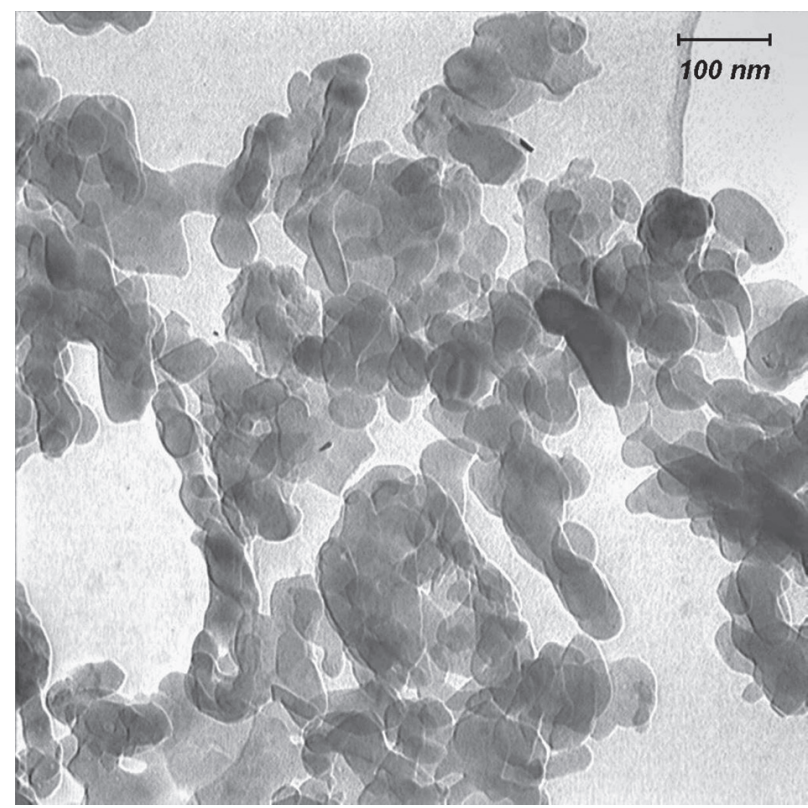

Figure 2. TEM micrograph of the synthesized forsterite.

Figure 3 illustrates XRD pattern for forsterite/ UHMWPE composite. This figure shows that extrusion operation, compression molding and laboratory condition of the experiment haven't had any undesired effects on primary materials used in producing composite. No pollution or secondary destructive phase was observed in the temperature and operating condition of extrusion. According to this figure, there are two high peaks in the range of $20<2 \theta<28$ degrees which are related to UHMWPE. Other small peaks in the range of $20<$ $<2 \theta<80$ degrees are related to forsterite that performs as composite reinforcement. The height of peaks and their angles confirm the expected quantity and quality analysis of the composite. Taken the fact that the specimens picked up for XRD test were randomly selected from the produced composite sheet, they can be regarded as a representative sample which confirms uniform dispersion of forsterite in the matrix. Sizes of forsterite crystallites existing in UHMWPE matrix were computed with the help of Williamson-Hall Equation and again it was equal to $30 \mathrm{~nm}$ which shows that production process of composite has no effect on the size of crystallites in forsterite microstructure; this certifies that our applied production procedure only determines mechanical pro-perties and does not affect any biological features. Hence, the method used to produce Forsterite-Poly Ethylene nano-composite is an appropriate one that was benefitted from in this study.

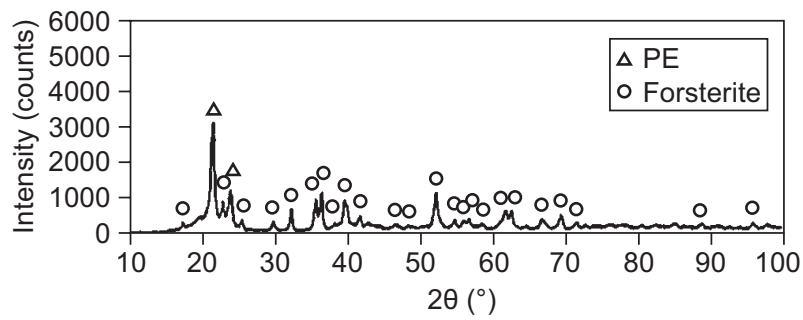

Figure 3. XRD pattern of the forsterite/UHMWPE composite.

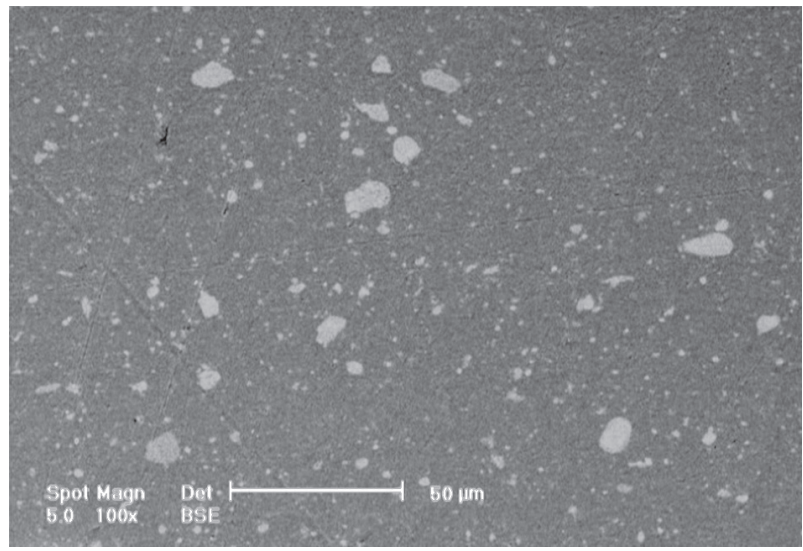

a) plan

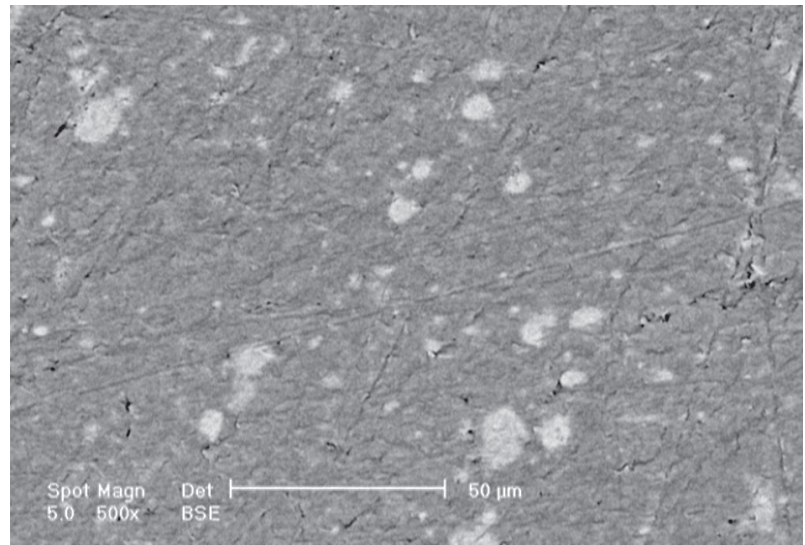

b) cross section

Figure 4. SEM Microstructure of the forsterite/UHMWPE composite film: a) plan; b) cross section.

Basically, the parameters affect mechanical properties of reinforced composites are size scale and uniform dispersion of reinforcing particles in the matrix $[8,9]$; therefore, using a SEM microscope, size scale 
and distribution of forsterite particles in the matrix were studied. Figure 4a represents SEM picture of bulk composite samples randomly selected from the original sheet. The picture shows that although forsterite particles have agglomerated in some areas due to extrusion process and compression and operating temperature, the distribution of forsterite particles in the matrix are still acceptable. Note that the agglomeration of forsterite is only surface adhesion of particles which doesn't change crystallite size and hence, doesn't affect biological properties [21, 22]. Furthermore, based on the picture, the average size of reinforcing particles is less than $1 \mu \mathrm{m}$ which is a suitable size to reach expected mechanical properties for the composite [3]. Figure $4 \mathrm{~b}$ shows the cross section of the composite. It also can be seen that forsterite nano-crystallites have uniformly dispersed in the cross section. In addition, the figure illustrates appropriate tangling between dispersed reinforcing particles and matrix which in turn causes improvement in mechanical properties of the produced composite. From this angle of view, again the average size of reinforcing particles of our composite is less than $1 \mu \mathrm{m}$.

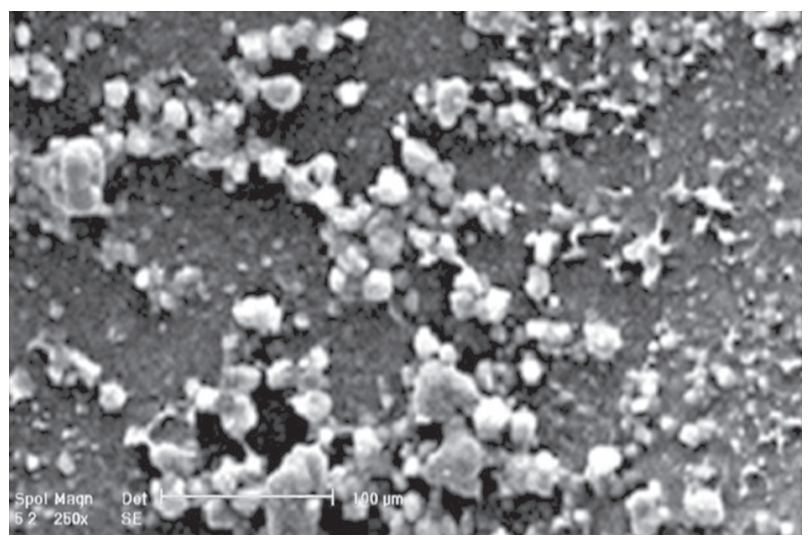

a)

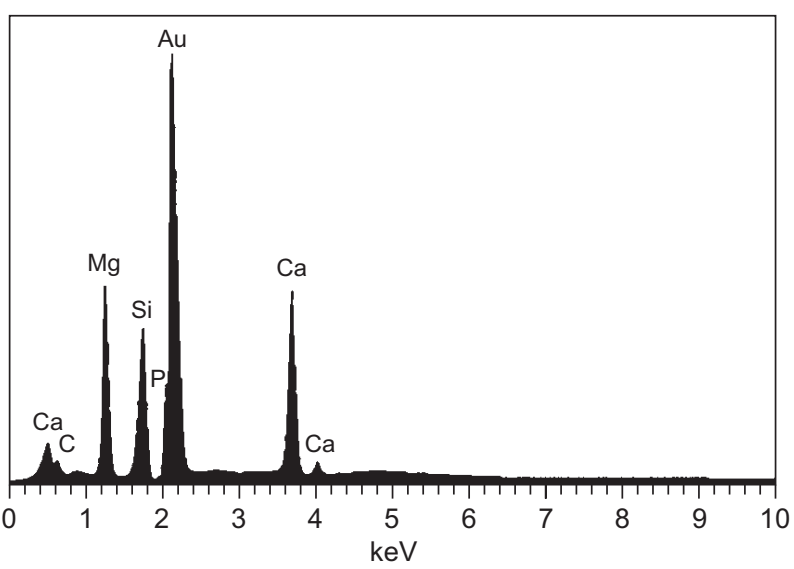

b)

Figure 5. SEM photograph and EDX spectrum of the forsterite/UHMWPE composite after immersion in SBF solution for 28 days.

\section{In Vitro Bioactivity}

EDX spectra along with the morphology of composite after 28 days floating in SBF solution are presented in Figure 5. SEM picture shows tiny particles which precipitate on the surface of the composite. The EDX analysis confirms the presence of Calcium and Phosphorus in the ball-like particles and indicates that they are mostly made up of these two elements. It should be noted that the presence of $\mathrm{Mg}$ and $\mathrm{Si}$ in the EDX spectra originates from the remained forsterite. These findings verify that forsterite particles of the composite could successfully react with the SBF solution to produce bone-making elements which proves the bioactivity of the composite.

Figure 6 illustrates X-ray diffractometer pattern of a forsterite/UHMWPE composite sample both before and after its 28-day floating in SBF solution to identify phases produced by bioactivity evaluation test. The comparison between these two patterns demonstrates a new sharp peak and two other shorter ones in the range of $25<2 \theta<35$ degrees after 28 days floating in SBF solution. These peaks reveal the presence of Calcium ion and Phosphate group.

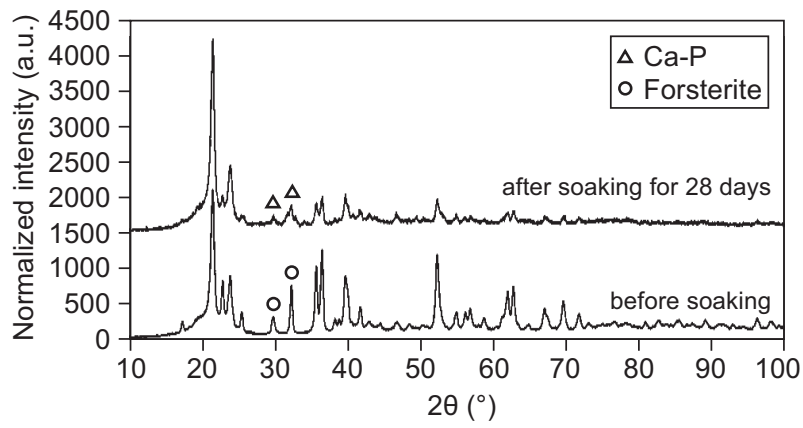

Figure 6. XRD patterns of forsterite/UHMWPE composite surface before and after SBF immersion (28 days).

Another point that can be inferred from the XRD pattern is that the forsterite peaks intensities have reduced after 28 days which is due to two main reasons; first, the forsterite crystallites have reacted with SBF solution and transformed to Calcium ion and Phosphate group; second, the precipitated productions on the surface of the sample cause diffraction of X-ray waves to other angles.

\section{PH Changes}

Figure 7 shows changes of $\mathrm{pH}$ of $\mathrm{SBF}$ solution during 28 days. It can be seen that the $\mathrm{pH}$ on the first 12 days has increased. This is due to dissolution of $\mathrm{Mg}$ ions from the forsterite crystallites and corresponding production of Calcium ions and Phosphate groups; however, the slope of the diagram has decrease gradually which is because of both consumption of forsterite 
crystallites and creation of Calcium and Phosphate precipitates on surface of the sample; this precipitation has caused reduction of dissolution of $\mathrm{Mg}$ from forsterite crystallites and simultaneous reduction of $\mathrm{Ca}-\mathrm{P}$ production. According to Figure 7, the decrement of the slope of the diagram has continued for 12 days until the $\mathrm{pH}$ has become stable.

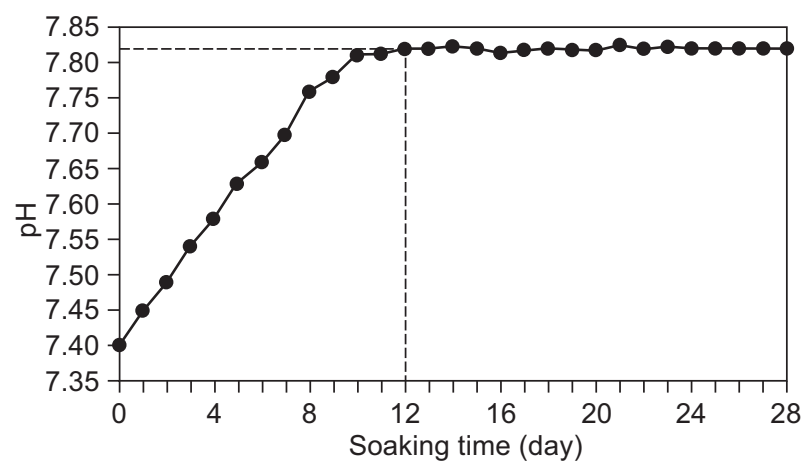

Figure 7. $\mathrm{pH}$ changes of the SBF solution after soaking the composite for 28 days.

\section{Mechanical Properties}

Figure 8 presents typical stress-strain curves for the composite and pure UHMWPE prepared in a similar procedure (compression molding and swelling extrusion) due to comparison purposes. Mechanical properties of the composite and pure UHMWPE along with those for cortical bone are also summarized at Table 1. Results show that the Young's modulus of the

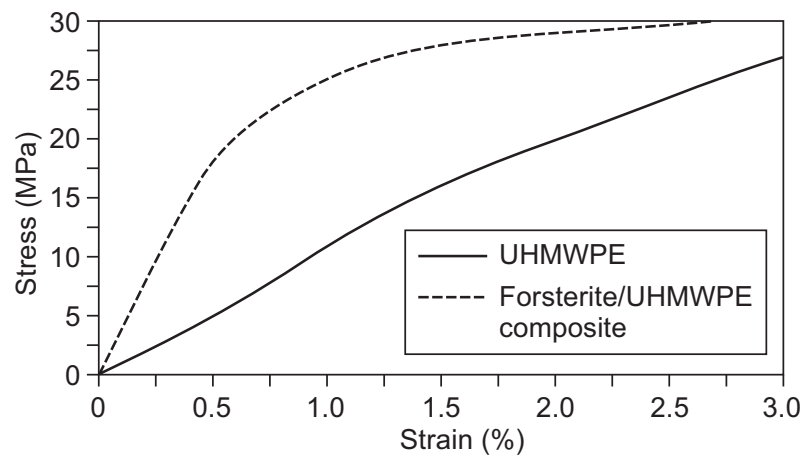

Figure 8. Typical tensile stress/strain curves of the pure UHMWPE and the forsterite/UHMWPE composite.

Table 1. Mechanical properties of pure UHMWPE, forsterite/ UHMWPE composite and cortical bone.

\begin{tabular}{lccc}
\hline & $\begin{array}{c}\text { Young's } \\
\text { modulus } \\
(\mathrm{GPa})\end{array}$ & $\begin{array}{c}\text { Yield } \\
\text { strength } \\
(\mathrm{MPa})\end{array}$ & $\begin{array}{c}\text { Fracture } \\
\text { strain } \\
(\%)\end{array}$ \\
\hline UHMWPE & $0.9 \pm 0.3$ & $27.5 \pm 0.4$ & $480 \pm 28$ \\
Forsterite/UHMWPE & $10.6 \pm 0.7$ & $33.1 \pm 1.5$ & $321 \pm 20$ \\
Cortical bone & $7-30$ & $50-150$ & $1-3$ \\
\hline
\end{tabular}

composite is about twelve times more than that of pure UHMWPE. This value agrees with the range of Young's modulus of cortical bone; so it can be concluded that it will prevent stress shielding phenomenon in case of implementation [15].

According to the results, the yield stress of forsterite (50 vol. \%)/UHMWPE composite has not considerably changed in comparison with pure UHMWPE. It is also seen that adding 50 volume percentage of forsterite particles to UHMWPE matrix has substantially decreased its fracture strain; however, it is still more than $300 \%$ which is very high for this amount of forsterite as reinforcement. In addition, the fracture strain of composite is much higher than that of cortical bone which resulted in superior toughness of composite. Basically, the high toughness of composite is due to uniform distribution of forsterite nano crystallites in the matrix which effectively restrain generation and growth of micro-cracks during tensile test. Results confirm allowance of using $50 \mathrm{vol}$. \% of reinforcement in a forsterite/UHMWPE system without considerable ductility reduction.

\section{CONCLUSIONS}

UHMWPE reinforced by $50 \%$ volume percentage of forsterite nano crystallite was fabricated using twinscrew extruder and compression molding. The results of the test-studies brought us to conclude that:

- The method used to produce this composite caused homogenous dispersion of reinforcements in the matrix.

- The composite showed a satisfactory in vitro bioactivity resulted from reaction between forsterite nano crystallites and SBF solution.

- No reduction was found in the yield strength of composite compared to pure UHMWPE; in addition, its ductility was also approximately maintained. The composite also exhibited high toughness and Young's modulus comparable to that of cortical bone.

\section{REFERENCES}

1. Evans S.L., Gregson P.J. (1998): Composite technology in load-bearing orthopaedic implants. Journal of Biomaterials, 29, 1329-42. doi:10.1016/S01429612(97)00217-2

2. Ramakrishna S., Huang Z.M., Kumar G.V., Batchelor A.W., Mayer J. (2004). An introduction to biocomposites, Imperial College Press, London.

3. Liming F., Ping G., Yang L. (2007): High strength and bioactive hydroxyapatite nano-particles reinforced ultrahigh molecular weight polyethylene. Composites Part B: Engineering, 38(3), 345-351. doi:10.1016/j.compositesb. 2006.05.004 
4. Fang L.M., Leng Y., Gao P. (2006): Processing and mechanical properties of HA/UHMWPE nanocomposites. Biomaterials, 27(20), 3701-3707. doi:10.1016/j.biomaterials.2006.02.023

5. Abu Bakar M.S., Cheang P., Khor K.A. (2003): Mechanical properties of injection molded hydroxyapatitepolyetheretherketone biocomposites. Composites Science and Technology, 63,421-425. doi:10.1016/S0266-3538(02) 00230-0

6. Cheang P., Khor K.A. (2003): Effect of particulate morphology on the tensile behaviour of polymer-hydroxyapatite composites. Materials Science and Engineering: A, 345(1), 47-54. doi:10.1016/S0921-5093(02)00284-8

7. Wang M., Bonfield W. (2001): Chemically coupled hydroxyapatite-polyethylene composites: structure and properties. Biomaterials, 22(11), 1311-1320. doi:10.1016/ S0142-9612(00)00283-0

8. Wang M., Joseph R., Bonfield W. (1998): Hydroxyapatitepolyethylene composites for bone substitution: effects of ceramic particle size and morphology. Biomaterials, 19(24), 2357-2366. doi:10.1016/S0142-9612(98)00154-9

9. Roeder R.K., Sproul M.M., Turner C.H. (2003): Hydroxyapatite whiskers provide improved mechanical properties in reinforced polymer composites. Journal of Biomedical Materials Research Part A, 67(3), 801-812. doi:10.1002/jbm.a.10140

10. Ji B.H., Gao H.J. (2004): Mechanical properties of nanostructure of biological materials. Journal of the Mechanics and Physics of Solids, 52(9), 1963-1990. doi:10.1016/j.jmps.2004.03.006

11. RhoJ.Y.,Kuhn-Spearing L.,Zioupos P.(1998):Mechanical properties and the hierarchical structure of bone. Medical engineering \& physics, 20(2), 92-102. doi:10.1016/S13504533(98)00007-1

12. Weiner S., Wagner H.D. (1998): The material bone: structure-mechanical function relations. Annual Review of Materials Science, 28(1), 271-298. doi:10.1146/annurev. matsci.28.1.271

13. Suchanek W., Yoshimura M. (1998): Processing and properties of hydroxyapatite-based biomaterials for use as hard tissue replacement implants. Journal of Materials Research, 13(01), 94-117.
14. Murugan R, Ramakrishna S. (2004). Nanostructured biomaterials, p.595-613, American Scientific Publishers, California.

15. Murugan R., Ramakrishna S. (2005): Development of nanocomposites for bone grafting. Composites Science and Technology, 65(15), 2385-2406. doi:10.1016/j. compscitech.2005.07.022

16. Ni S., Chou L., Chang J. (2007): Preparation and characterization of forsterite $\left(\mathrm{Mg}_{2} \mathrm{SiO}_{4}\right)$ bioceramics. Ceramics International, 33(1), 83-88. doi:10.1016/j.ceramint. 2005.07.021

17. Fathi M.H., Kharaziha M. (2009): Two-step sintering of dense, nanostructural forsterite. Materials Letters, 63(17), 1455-1458. doi:10.1016/j.matlet.2009.03.040

18. Knepper M., Moricca S., Milthorpe B.K. (1997): Stability of hydroxyapatite while processing short-fibre reinforced hydroxyapatite ceramics. Biomaterials, 18(23), 15231529. doi:10.1016/S0142-9612(97)80003-8

19. Ni S., Chang G., Chou L. (2008) : In vitro studies of novel $\mathrm{CaO}-\mathrm{SiO} 2-\mathrm{MgO}$ system composite bioceramics. Journal of Materials Science: Materials in Medicine, 19(1), 359367. doi:10.1007/s10856-007-3186-3

20. Osborn J.F., Neweseley H. (1980). The material science of calcium phosphate ceramics. Biomaterials, 1(2), 108-111. doi:10.1016/0142-9612(80)90009-5

21. Kharaziha M., Fathi M.H. (2009): Synthesis and characterization of bioactive forsterite nanopowder. Ceramics International, 35(6), 2449-2454. doi:10.1016/j.ceramint. 2009.02.001

22. Tavangarian F., Emadi R. (2010): Synthesis of nanocrystalline forsterite $\left(\mathrm{Mg}_{2} \mathrm{SiO}_{4}\right)$ powder by combined mechanical activation and thermal treatment. Materials Research Bulletin, 45(4), 388-391. doi:10.1016/j.materresbull.2009.12.032

23. JCPDS Card No. 34-0189, 1984.

24. American Society of Testing and Materials (ASTM). Standard Test Method for Tensile Properties of Plastics. ASTM D638-10, West Conshohocken, PA, 2010. doi:10.1520/D0638-10.

25. Kokubo T., Takadama H. (2006): How useful is SBF in predicting in vivo bone bioactivity?. Biomaterials, 27(15), 2907-2915. doi:10.1016/j.biomaterials.2006.01.017 